\title{
分析核桃病虫害防治策略
}

\author{
何绍书
}

六盘水市钟山区自然资源局

DOI:10.32629/as.v3i1.1740

[摘 要] 核桃树对于我国多种土壤都广泛适应,并且该树种的寿命相对较长。核桃树属于胡桃科植物,在一些相对比较温暖和千燥的地区,核桃 树得到了大量种植。核桃中含有较高含量的亚油酸, 可以有效降低人体内的胆固醇, 同时核桃中含有的磷脂和蛋白质含量较高, 可以对人类大脑 发育起到促进作用,其属于一种公认的补脑食物 ${ }^{[1]}$ 。在我国的几千年历史中, 核桃都是餐点食品中比较重要的一种原料, 由于核桃的营养价值较高, 深受人们喜爱, 所以核桃的经济价值也随之增高, 因此我国各大地区都开始了核桃种植, 而要想进一步促进核桃产业的稳定发展, 就需要加强对病 虫害的防治,应用科学合理的病虫害防治策略,为核桃种植产量提供进一步保障。

[关键词] 核桃; 病虫害; 防治策略

核桃树作为一种胡桃科植物, 比较喜爱温暖的气候, 其寿命可以达到 上百年, 对于生活地区的土壤要求相对较低, 具有非常高的经济价值, 并且 营养丰富, 所以在我国被大范围的栽种 ${ }^{[2]}$ 。但是随着核桃种植面积的逐渐 扩大, 核桃的病虫害种类也越来越多, 因此为了有效提高核桃的种植成功 率, 使核桃成果质量显著提升, 就需要加强对核桃病虫害的深入了解与分 析, 选择更恰当的核桃栽种时间, 对核桃病虫害防治技术进行合理掌握, 对 物理、化学和生物等多种防治技术进行综合运用, 有效改善核桃树体的生 长环境, 使核桃病虫害防治效果得到进一步强化, 最终生产出更加优质的 核桃。

\section{1 核桃的病虫害种类}

1. 1 核桃瘤蛾

核桃瘤蛾幼虫属于一种暴食性害虫, 会对核桃嫩叶进行食用, 导致核 桃嫩叶被快速吃光, 而在核桃树再次长出嫩芽时, 其长势就会相对减弱很 多, 甚至会有大部分核桃树, 在被核桃瘤蛾啃食嫩叶后第二年就会枯死 ${ }^{[3]}$ 。 核桃瘤蛾的主要防治方法就是对物理方法进行应用, 将石块堆积在核桃树 周围, 在核桃瘤蛾熟幼虫化蛹时, 就可以对其进行诱杀, 在利用化学方法进 行防治时, 就可以对 $50 \%$ 杀蛽松乳油 1000 倍液进行喷酒, 或者喷酒 $90 \%$ 晶体 敌百虫 800 倍液, 还可以对 $2.5 \%$ 溴氰菊酯乳油 6000 倍液进行应用。

\section{2 核桃举肢蛾}

举肢蛾虫主要是对核桃的果实进行啃食, 严重危害到核桃果实的生长, 在核桃青果实内进入了举肢蛾虫幼虫后, 就会对核桃果实肆意食用, 并且

为降低疾病对水稻产量和品质造成的影响, 需要选择抗病虫害比较强 的水稻种子, 结合水稻种子特点, 对纹枯病合理防治, 在水稻孕穗期间, 适 量喷酒三唑酮药物, 剂量控制在 $2000 \mathrm{~g} /$ 公顷。严格防治稻瘟病, 对选择的稻 种进行消毒处理, 结合当地稻瘟病实际情况, 开展有针对性的防治管控。同 时也要做好肥料及灌溉水的管理工作, 保证水稻生长对养分、水资源的需 求。三环唑喷酒剂量为 $200 \mathrm{~g} /$ 公顷。

通过适量喷酒防蛙虫药, 防治蛙虫侵害隧道, 合理防治三种化学蛙虫 和两种化学蛙虫。切实做好蛙虫产卵防治工作, 从蛙虫源头上控制和消除 害虫对水稻造成的影响 ${ }^{[5]}$ 。在水稻分菜期, 要进行科学合理的病虫害防治, 合理选择药剂及剂量, 尽量选择无公害, 少残留药剂, 保证水稻安全, 提升 食用价值。在病虫害防治时, 要严格遵循科学、合理、现代化原理, 结合多 种先进的防治技术共同使用, 实现对病虫害的科学化防治。

\section{3 结束语}

综上所述, 本文结合理论实践, 研究了水稻的高产技术, 研究结果表明,
会在核桃果实内留下粪便, 导致核桃青果实在生长过程中越来越黑, 其在 还没有成熟时就会逐渐脱落, 即使其果实不会脱落, 也不存在相应价值 ${ }^{[4]}$ 。 因此就需要积极防治举肢蛾虫, 可以摘下核桃病果, 对其病果深埋, 同时要 集中焚烧核桃的枯枝落叶, 对即将越冬的幼虫及时杀死。还要在春季科学 修剪相应病枝, 保证核桃树的水分充足, 对果园内的杂草进行清理, 尽可能 的减少病虫。还可以在 4 月份对辛硫磷微胶囊 3000 倍液进行喷酒, 将其在树 盘周围进行喷酒, 将刚刚越冬后的幼虫及时杀死, 还要在夏天对杀虫剂进 行喷酒, 有效防治虫害。

\section{3剌蛾类虫害}

刺蛾又名羊拉子, 在全国各地都存在, 对核桃树叶片比较喜爱, 在一定 程度上威胁了核桃树成长, 导致核桃树产量有所下降 ${ }^{[5]}$ 。刺蛾主要会影响 核桃树叶部位, 刺蛾在幼虫时期会对核桃树叶的表皮和叶肉部分进行食用, 导致核桃叶片上存在较多的洞, 严重影响到核桃树长势。刺蛾上存在相应 毒毛, 会对人类皮肤造成刺激, 导致人们感觉到疼痛。对刺蛾的物理防治方 法是对虫茧进行修剪, 然后将其进行深埋, 或者摘除存在大片刺蛾的核桃 叶片, 将其处死, 或者利用黑光灯, 对刺蛾成虫进行诱杀。如果刺蛾的幼虫 危害比较严重, 可以在幼虫发生期间, 对 $25 \%$ 亚胺硫磷乳油 600 倍液进行喷 酒, 或者应用 $48 \%$ 乐斯本乳油 2000 倍液。

1. 4 腐烂病

核桃出现腐烂病的主要原因是由于感染了真菌, 枝干属于腐烂病的主 要危害部位, 腐烂病的发病高峰期为春季和秋季, 在核桃枝条染上了腐烂 民经济水平, 促使我国农业经济持续发展。水稻高产技术要从多方面同时 入手, 包括培育壮积技术、移栽技术、田间管理技术、病虫害防治技术等, 从根本上提升水稻产量, 促使我国水稻种植事业良性发展。

\section{[参考文献]}

[1]陈杏山,郭美华.探讨水稻高产技术精确定量栽培的发展及推广 [ J]. 种子科技,2018(1):26.

[2]陈文炬.水稻种植高产技术的新发展[J].农民致富之友,2017(14):143.

[3]袁少荣, 黄燕平, 粱东明, 等. 中国水稻高产栽培技术创新与实践 [J]. 农业开发与装备,2017(11):165.

[4]陶西林,魏秀翠,陈芹,等.水稻机插种的优势及高产栽培技术 [J].乡 村科技,2017(16):55-56.

[5]李先祥, 李才勇.华坪县两万亩水稻创高产[J]. 农民致富之 友,2017(10):41-42. 
病时, 其枝条会干枯, 存在黑色小点, 或者是在核桃树的剪锯口处出现比较 明显的病斑, 其病斑会逐渐向下暻延 ${ }^{[6]}$ 。针对核桃腐烂病, 就可以进行深翻 改土, 适当施加有机肥, 可以在冬夏季涂白树干。对于已经发生腐烂病的核 桃树, 首要就是刮除病斑, 在刮除完成后, 就可以涂抹 $40 \%$ 晶体石硫合剂 $20 \sim 30$ 倍液, 或者对多菌灵可湿粉剂1000倍液进行应用。

\section{5 黑斑病}

黑斑病还可以称之为细菌性黑斑病或黑腐病, 会对核桃果实、叶片和 枝条造成危害。一般会发生在 5 月中下旬, 其发病盛期会在 $6 \sim 7$ 月。当核桃 果实出现黑斑病时, 其果实就会出现微小突起的黑褐色小斑点, 并且其小 斑点会逐渐扩大, 最终形成不规则的黑斑, 严重时其黑斑会有所下陷, 导致 核桃果实由外向内逐渐腐烂。在核桃叶片出现黑斑病后, 叶片上就会出现 小黑斑, 然后其黑斑会逐渐扩大而接近原形, 导致核桃果实和叶片过早脱 落。针对核桃黑斑病, 就可以在每年秋季施加充足的有机肥, 还要对感染源 进行合理清除, 在核桃果实摘除后, 就要对染病的枝干、叶片和果实进行清 除, 并且对其进行集中的烧毁。在核桃树发芽前, 就可以对波美度石硫合剂 喷酒 $3 \sim 5$ 次, 在核桃树展叶后, 就可以对适量的波尔多液进行喷酒。

\section{2 核桃病虫害防治策略}

2. 1 注重对核桃各类病虫害发生规律的掌握

核桃发生病虫害时都存在一定的规律性, 因此就需要种植人员结合病 虫害的发生规律, 对其进行实时监控, 结合核桃病虫害的种类、分类和生活 规律等多种情况, 寻找出相应的病虫害发生规律, 对其进行及时有效的防 治。核桃树还存在比较明显的病虫害季节规律, 核桃树在春夏秋冬各个季 节存在不同的生长规律, 其病虫对核桃根部、枝叶和果实的危害也存在一 定差异, 同时还要结合病虫的相关特定, 对其进行有效防治。在核桃树生长 过程中, 为其创造良好的通风条件, 保持充足的阳光, 对核桃树生长起到一 定的促进作用, 还要保证核桃树在生长过程中具有充足的水分, 破坏病虫 的繁殖条件, 使核桃树的病虫害抵抗能力逐渐提升。

\section{2 加强对各类植物的检疫}

核桃种植人员还要在核桃苗的源头, 对其质量进行严格把控, 杜绝在 病虫害区域进行核桃苗木的采购, 在核桃树苗运输完成后, 要对其进行有 效检疫, 一旦幼苗出现了相关问题, 就要对其进行及时的销毁, 严谨传播和 扩散携带病虫害的核桃幼苗。对核桃幼苗质量进行严格把控。

2. 3合理运用物理方法进行病虫害防治

针对一些核桃害虫, 可以利用光、色和味等趋性诱杀方式, 或者对人工 捕杀的方式进行应用, 而针对铜绿金龟等虫害, 就可以利用震动的方式, 使 其害虫可以落下来, 然后再将害虫杀死。还可以在核桃树基部涂抹上胶,
避免害虫爬到树上, 可以在核桃园内对黑光灯进行安装, 对其害虫进行诱 杀。还可以对相关病虫害的树枝进行修剪, 摘除受到病虫害侵害的果实与 叶片, 对其进行集中焚烧, 或者进行深度掩埋。

2. 4 科学利用化学药剂进行病虫害防治

针对大面积的核桃病虫害, 其化学药剂的防治效果相对较好, 可以在 较短时间内对病虫害进行控制。但是对化学药剂大量的使用, 就会出现一 系列的负面效应, 一些农药在核桃果实内残留, 就会对人体造成伤害。同时 对一类化学试剂进行长期的使用, 就会导致病虫产生相应的抗药性, 导致 后期的防治效果有所下降。但是由于化学药剂的防治方法比较简单, 并且 可以实现机械化操作, 所以在当前的核桃病虫害防治中, 其化学药剂仍然 具备比较重要的作用。在对化学试剂防治方法进行应用时, 就要注意对不 同的化学药剂进行交替使用, 同时要对化学药剂用量进行正确的使用, 尽 可能降低化学药剂对人体的伤害。

2.5 有效应用生物防治方法

对于核桃病虫害, 可以考虑对鸟、菌和虫等方式进行病虫害治理, 这种 治理方式不会使核桃种植区域的生态平衡受到破坏, 还不会对环境造成污 染, 可以有效促进种植区域的可持续发展。一般情况下需要在病虫害发病 初期和病虫害低龄阶段应用生物防治方法, 其需要结合核桃实际生长情况, 对其进行合理调配, 避免该方法与碱性农药混合使用, 利用病虫害天敌消 灭病虫为比较常用的生物防治方法。

\section{3 结束语}

对核桃病虫害进行有效防治, 可以使病虫害对核桃产量与品质的损害 得到有效降低, 但是在病虫害的防治过程中, 要避免对化学药剂的滥用, 加 强对病虫害规律的了解, 对防治方法进行合理选择, 对生态环境有效保护, 促进核桃种植业的稳定发展。

\section{[参考文献]}

[1]祝清芳.核桃病虫害防治技术及防治策略[0].科技风,2019,(34):123.

[2]黄万斌。核桃栽培及病虫害防治对策探究 [J]. 农业与技 术,2019,39(06): $61+63$.

[3]余金勇,吴跃开,朱秀娥,等.贵州核桃病虫害及防治策略[J].贵州林 业科技,2018,46(02):58-60.

[4]姜斌.核桃主要病虫害防治技术[J].农业开发与装备,2019,(11):183-184.

[5]吐尔孙・吾布力.核桃病虫害栽培防治技术探究 [J].农家参 谋,2019,(17):54.

[6]张举, 孙贤.核桃栽培及病虫害防治方法探讨 [J]. 农家参 谋,2019,(16):113. 